http://journals.ums.ac.id/index.php/ijolae

\title{
Fostering Germane Load Through Self-explanation Prompting in Calculus Instruction
}

\author{
Cecep Anwar Hadi Firdos Santosa1, Sufyani Prabawanto², Indiana Marethi ${ }^{3}$ \\ ${ }^{1,3}$ Faculty of Education, \\ University of Sultan Ageng Tirtayasa, Indonesia \\ ${ }^{2}$ Mathematical Education and Natural Science \\ Indonesia University of Education, Indonesia
}

DOI: 10.23917/ijolae.v1i1.7421

Accepted: Januari 02 $2^{\text {th }}, 2019$. Approved: March 09 ${ }^{\text {th }}, 2019$. Published: March $11^{\text {th }}, 2019$

\begin{abstract}
The purpose of this research was to investigate the effect of self-explanation prompting to students' germane load while studying mathematics in the multivariable calculus course. This research employed a quasiexperimental method with matching-only posttest-only control group design. The subject of the research consists of 72 first-year mathematics education undergraduate students. The results indicated that there was no significant difference in students' germane load between students who implemented worked-example with self-explanation prompting and students who implemented worked-example without self-explanation prompting. However, it was revealed that the students' germane load was categorized high in both classes. It indicates that the worked-example method could foster students' germane load. Nonetheless, these results cannot be evidence that self-explanation prompting is capable to foster students' germane load. However, there is an association between germane load and learning objectives. When students achieve the learning objectives, then its learning method is able to foster the germane load. To assess the learning objectives, the posttest was arranged. The results stated that students who implemented the worked-example method with self-explanation prompting had better test scores than students who implemented the worked-example method without self-explanation prompting. This result was sufficient to provide evidence that the use of worked-example with self-explanation prompting could foster students' germane load students in the multivariable calculus course.
\end{abstract}

Keywords: Germane load, Worked-example, Self-explanation prompting

Corresponding A uthor:

Cecep Anwar, Faculty of Education, Universitas Sultan Ageng Tirtayasa., Indonesia

e-mail : cecepanwar@untirta.ac.id

\section{Introduction}

Multivariable calculus is one of the compulsory subjects that must be completed by mathematics education department students. The basics for studying calculus have been studied by them at secondary school. However, there are fundamental differences between mathematics in secondary schools and university. Mathematics in university is more formal, rigor, and deductive compared to mathematics at secondary school.
(Moore, 1994; Tall, 2008). In addition, to succeed in this course, students must grasp several prerequisite concepts, including the concepts of function (Kashefi, Ismail, \& Yusof, 2010), algebra, analytical geometry, and trigonometry (Stewart, 2012).

Therefore, calculus courses (including multivariable calculus) are often considered as the difficult subject for students (Job \& Schneider, 2014; Martínez-Planell, Gonzalez, DiCristina, \& Acevedo, 2012; Moru, 
2009; Nursyahidah \& Albab, 2017; Orton, 1983; Santosa, 2013). In general, there are at least three sources of learning difficulties in mathematics (Debue \& Leemput, 2014; Khateeb, 2008; Sweller, 2008), that comes from mathematics itself, the way the material of mathematics is delivered, and cognitive difficulties in forming the schema when dealt with new information.

The first difficulty occurs because of many elements or mathematical material that interact with each other or which must be processed simultaneously in students' cognitive, both the prerequisite material and the new material being studied. The source of this difficulty is practically unavoidable because it adheres to mathematics as a complex discipline. Thus, the source of this difficulty is known as intrinsic difficulty (Leahy \& Sweller, 2008; Sweller, 2010).

Furthermore, the second source of difficulty relates to the method or method used to learn calculus. The selection of the appropriate teaching method influences success in learning. Since humans have limitations while processing information (Baddeley, 1992, 2003, 2010, 2012). Old research by (Miller, 1956) and (Peterson \& Peterson, 1959) states that humans are only able to store $7 \pm 2$ information in one process and can only preserve about 30 seconds. Thus, the second type of difficulty is called extrinsic difficulty (Mattys, Barden, \& Samuel, 2014; Paas \& Kester, 2006).

Contrasting the previous two difficulties, the third difficulty is related to the formation of a knowledge scheme. At that time, students invested a mental effort that was used to create knowledge schemes and solve the relevant problems. Certainly, the greater the mental effort that is organized, the more possible someone is to be able to solve problems and form new knowledge in his mind. This type of difficulty is called germane difficulty or relevant difficulty (Debue \& Leemput, 2014).
These three sources of difficulty cause cognitive load (Sweller, 2011; Sweller \& Sweller, 2006). Cognitive load is related to one's mental effort when processing information. High cognitive load without being followed by the formation of a knowledge scheme causes cognitive inefficiency. In this condition, the mental effort is too high compared to the achievement. Of course, this condition is an undesirable condition and must be avoided in the learning process.

Furthermore, of the three characteristics of the cognitive load, intrinsic cognitive load is a cognitive load that is difficult or even cannot be intervened through learning methods. Conversely, extrinsic cognitive load is a source of cognitive load that can be intervened by an appropriate learning method. Through the use of these learning methods, it is expected that extrinsic cognitive load can be reduced. In contrast to the two types of cognitive load previously, the relevant cognitive load (germane) must be fostered (Debue \& Leemput, 2014), considering the mental effort that is deployed for this cognitive load is closely related to the success of establishing schemes of knowledge and success in solving problems.

The learning method which is empirically to have the ability to reduce extrinsic cognitive load is worked-example method (Bokosmaty, Sweller, \& Kalyuga, 2015; Booth, Lange, Koedinger, \& Newton, 2013; Hu, Ginns, \& Bobis, 2015; Renkl, 2017; Retnowati, Ayres, \& Sweller, 2010; Rourke \& Sweller, 2009; Salden, Koedinger, Renkl, Aleven, \& McLaren, 2010; Santosa, Suryadi, Prabawanto, \& Syamsuri, in press.; Van Gog, Kester, \& Paas, 2011; Yanuarto, 2016). Worked-example is "a step-by-step demonstration of how to perform a task or solve a problem" (Clark et al., 2011, p. 190). By studying the worked-example, knowledge schemes will be more easily and rapidly obtained by students. 
Besides that, the important thing to notice is the relevant cognitive load (germane). Previous studies state that the use of the worked-example is able to reduce extrinsic cognitive load, but it is not guaranteed that this method can also foster relevant cognitive loads. In principle, the learning process using worked-example is considered to help students understand the concepts that have been taught by encouraging them to do selfexplanation. Self-explanation can be interpreted as a process of generating explanations on oneself as an attempt to understand the concepts that are being studied, associating with prior knowledge, and refining mental models (Rittle-Johnson, Loehr, \& Durkin, 2017).

At present, almost all calculus textbooks seem to have implemented the workedexample method. For example, books written by (Purcell, Varberg, \& Rigdon, 2007) and (Stewart, 2012) have even been translated into Indonesian. However, students still face difficulties in understanding worked-example presented.

Therefore, an appropriate method is needed to help students do self-explanation. One of these methods is to provide selfexplanation prompting. Several studies have shown the success of this method, including research by (Rau, Aleven, \& Rummel, 2015) on algebra course, (Hodds, Alcock, \& Inglis, 2014) to improve mathematical proofing abilities and other related studies (Berthold, Röder, Knörzer, Kessler, \& Renkl, 2011; Hefter et al., 2015; RittleJohnson et al., 2017; Roelle, Hiller, Berthold, \& Rumann, 2017).

Although there has been a lot of research related to self-explanation prompting along with the use of worked-example, few of them focused on germane cognitive load. Thus, this study was conducted to reveal the role of self-explanation prompting on the germane cognitive load in multivariable calculus instruction.

\section{Method}

\section{Participants}

Seventy-two first-year undergraduate students in one of a state university in Banten Province Indonesia took part in this research. All of the students enrolled multivariable calculus subject. The experimental class consists of thirty-nine, while the control class was thirty-seven students.

\section{Instruments}

The instruments used in this study were tests and non-test instruments. The test instruments provided were in the form of three problems relating to multivariable calculus which had been tested for validity and reliability. The validity of these items was 0.71 , 0.45 , and 0.73 , respectively, with a reliability coefficient was 0.61 . Thus, this instrument meets the criteria to use in research.

Meanwhile, non-test instruments were used to measure the students' germane cognitive load when solving mathematical problems. This instrument is a rating scale with nine response scales, one states a low mental effort and nine states a high mental effort. The germane load score category is shown in Table 1. This rating scale is asked after students work on test questions. This instrument has been tested for reliability by Santosa, Suryadi, and Prabawanto (2016) with reliability coefficient (Cronbach Alpha) was 0.82 (highly categorized).

\section{Teaching Material}

After students learn about the concepts/principles of the subject to be studied, students are presented with worked-example and problems related to the concepts learned. However, the worked-example in experimental class is combined with selfexplanation prompting. 
Table 1. Germane Load Score Categorization

\begin{tabular}{ll}
\hline Range Skor Germane Load & Category \\
\hline $1-3$ & Low \\
$4-6$ & Moderate \\
$7-9$ & High \\
\hline
\end{tabular}

\section{Experimental Design}

This research is an experimental research, specifically quasi-experimental and the research design is the matching-only posttest-only control group design. The research design diagram is as follows (Fraenkel, Wallen, \& Hyun, 2012):

\begin{tabular}{llll}
\hline Treatment group & $\mathrm{M}$ & $\mathrm{X}$ & $\mathrm{O}$ \\
\cline { 2 - 4 } Control group & $\mathrm{M}$ & $\mathrm{C}$ & $\mathrm{O}$ \\
\hline
\end{tabular}

The $\mathrm{M}$ in this design means that the subjects in each group have been matched (on certain variables) but not randomly assigned to the groups.

The experimental class obtained learning using the worked-example method with selfexplanation prompting. This means that each step of worked-example presented is completed by prompting to help students do self-explanation. Prompting used refers to research by (Hausmann, Nokes, VanLehn, \& Gershman, 2009), which contains questions to stimulate them to think (e.g. what are you applying on this step?). While in the control class, students are given a work-example without being provided with self-explanation prompting.

\section{Experimental Procedure}

After the experimental and control groups are determined, the first step of the research is to test the prior mathematical abilities between the two classes and categorize students' initial mathematical abilities. Then each class obtained the predetermined learning, worked-example method for the control class and worked-example with selfexplanation prompting for the experimental class. The end of the study was carried out posttest along with testing the mental effort that the students invested when completing the posttest. This experimental procedure was suggested by Paas and Gog (2006).

\section{Data Analysis}

The data obtained were scores of students' mental effort and posttest scores on learning outcomes. Mental effort scores are categorized as ordinal data while posttest scores are categorized as interval data. The data from the research results will be analyzed descriptively followed by inferential analysis.

Especially for mental effort data, which categorized as ordinal data, the data analysis is similar to data analysis for posttest data (parametric analysis). This is in accordance with the opinion of (Norman, 2010) which states that ordinal data can be processed using parametric statistics, especially if the response scale is more than five (Jamieson, 2004).

\section{Result and Discuss}

\section{Students' Prior Mathematical Ability}

Table 2 shows that descriptively, the mean and median prior mathematical abilities of the control group students are higher than the experimental group with the difference is 1.02 and 2.50 respectively. Whereas based on the size of the data distribution, the control group standard deviation is slightly lower than the experimental group and the experimental group range has the opposite value. From this description it can be seen that there is no high difference between the prior mathematical abilities of the control group and the experiment.

This condition is validated by statistical test results using the difference between two independent tests. Table 3 shows that there is no significant difference in the mean score of students' prior mathematical abilities between the control and experimental groups at $\alpha=5 \%$.

By obtaining this condition, Paas and Gog (2006) state that the results of this study will give a strong prediction about the effect 
of learning using self-explanation prompting to students' germane load.

This condition is validated by statistical test results using the difference between two independent tests. Table 3 shows that there is no significant difference in the mean score of students' prior mathematical abilities between the control and experimental groups at $\alpha=5 \%$

By obtaining this condition, Paas and Gog (2006) state that the results of this study will give a strong prediction about the effect of learning using self-explanation prompting to students' germane load.

Table 2. Description of Student's Prior Mathematical Ability Score between Control and Experiment Groups

\begin{tabular}{lll}
\hline Statistics & Control & Experiment \\
\hline Mean & 63.67 & 62.67 \\
Median & 62.50 & 60.00 \\
Std. Deviation & 8.31 & 9.26 \\
Range & 42.50 & 41.30 \\
\hline
\end{tabular}

Table 3. Test of the Difference between Means Score in Students' Prior Mathematical Ability

\begin{tabular}{ll}
\hline Statistics & Score \\
\hline df & 74 \\
$\mathrm{t}$ Stat & 0.50562 \\
$\mathrm{P}(\mathrm{T}<=\mathrm{t})$ two-tail & 0.614626 \\
$\mathrm{t}$ Critical two-tail & 1.992543 \\
\hline
\end{tabular}

Table 4. Description of Students' Germane Load Score between Control and Experiment Groups

\begin{tabular}{llll}
\hline Problem & Stat & Control & Experiment \\
\hline \multirow{3}{*}{1} & Mean & 7.84 & 8.03 \\
& Median & 8.00 & 8.00 \\
& Std. Dev. & 1.38 & 1.29 \\
& Range & 4.00 & 5.00 \\
& Mean & 8.32 & 8.33 \\
2 & Median & 9.00 & 9.00 \\
& Std. Dev. & 1.11 & 1.20 \\
& Range & 5.00 & 5.00 \\
& Mean & 8.03 & 8.33 \\
& Median & 9.00 & 9.00 \\
& Std. Dev. & 1.44 & 1.20 \\
& Range & 6.00 & 5.00 \\
\hline
\end{tabular}

\section{Students' Germane Load}

There are three problems provided to students. Each problem is provided with questions about the mental effort that is invested by them when solving the problems.
Table 4 shows the results of mental effort measurements that reflect the students' germane cognitive load. For the first problem, descriptively the mean score of germane cognitive load between the control and ex- 
periment group were categorized high, which is 7.84 for the control and 8.03 for the experimental group. While based on the measure of dispersion, the standard deviation of the control group is slightly higher than the experimental group, but vice versa for the range.

This result is similar to the students' germane load for the second and third problems. Descriptively, it can be seen that the average score for the control and experiment groups fall into the high category (Table 4). In addition, for standard deviation and range measures, there is a slight difference between the control and the experiment groups (Table 4).

Descriptive statistics results in Table 4 validated by inferential statistics in Table 5 .
Based on the table, there is no significant difference in students' germane load between control and experiment groups at $\alpha=5 \%$. Thus, the results indicate that there is no difference between the worked-example method with self-explanation prompting and workedexample without self-explanation prompting on the students' germane load. The important thing, these results show that both methods could foster students' germane load and maintain it in the high category.

This is in accordance with the research conducted by (Van Loon-Hillen, Van Gog, \& Brand-Gruwel, 2012), which states that learning that emphases on the use of workedexample will optimize students' germane cognitive load.

Table 5. Test of the Difference between Means Score in Germane Load

\begin{tabular}{llll}
\hline Statistics & BKG 1 & BKG 2 & BKG 3 \\
\hline $\mathrm{t}$ & -.613 & -.034 & -.971 \\
$\mathrm{df}$ & 74 & 74 & 74 \\
Sig. (2-tailed) & .542 & .973 & .334 \\
Mean Difference & -.18780 & -.00901 & -.28067 \\
Std. Error Difference & .30651 & .26514 & .28892 \\
\hline
\end{tabular}

\section{Students' Performance}

Previously it was discussed that there was no difference between the worked-learning method with self-explanation prompting and worked-example without self-explanation prompting to students' germane cognitive load. However (Kalyuga, 2011) states that germane load is closely related to the learning objectives achievement. For that reason, to reveal whether a learning method has an influence on students' germane load or not, we need to explore students' learning objective achievement.

To find out whether the learning objectives of multivariable calculus course are achieved or not, we have to arrange tests which the tests indicator derived from the learning objectives. Those tests are represented in the posttest. There are three problems that had prepared.

Table 6 shows the description of students' posttest score between control and experiment group. Based on the table, the results show that for the first problem, the average and median values of the experimental group are higher than the control group. The condition is similar for second and third problem, the students' cognitive load mean score who implement workedexample learning with self-explanation prompting is higher than students who implement worked-example without selfexplanation prompting.

The results of the descriptive analysis were validated by inferencing analysis in Table 7. Based on the table, for the first problem, the mean score of posttest achievement of the expe imental group was higher than the control group with a p-value $=0,000$ at $\alpha=5 \%$. Furthermore, for the second problem, the mean score of students' posttest achievement of the experimental group was higher than the control group with 
a $p$-value $=0.0005$ at $\alpha=5 \%$. Finally, for the third problem, the mean score of students' posttest achievement of the experimental group is higher than the control group with a $p$-value $=0,000$ at $\alpha=5 \%$. Thus, it can be interpreted that the students' learning objective achievement in the experimental group is better than the control group. It means that the use of self-explanation prompting on the worked-example method is able to foster students' germane load.

Table 6. Description of Students' Posttest Score between Control and Experiment Groups

\begin{tabular}{llrr}
\hline Problem & \multicolumn{1}{c}{ Statistics } & Control & \\
\hline \multirow{4}{*}{1} & Mean & 10.27 & 13.54 \\
& Median & 8.00 & 10.00 \\
& Std. Deviation & 3.20 & 3.85 \\
& Range & 12.00 & 8.00 \\
& Mean & 6.35 & 7.13 \\
2 & Median & 6.00 & 8.00 \\
& Std. Deviation & 0.95 & 1.00 \\
& Range & 4.00 & 2.00 \\
& Mean & 3.78 & 4.77 \\
3 & Median & 4.00 & 4.00 \\
& Std. Deviation & 0.79 & 0.99 \\
& Range & 4.00 & 2.00 \\
\hline
\end{tabular}

Table 7. Test of Difference between Mean Score of Students' Posttest in Multivariable Calculus

\begin{tabular}{lrrr}
\hline Statistics & Masalah 1 & Masalah 2 & \multicolumn{1}{c}{ Masalah 3 } \\
\hline $\mathrm{t}$ & -4.030 & -3.466 & -4.830 \\
$\mathrm{df}$ & 72.774 & 73.999 & 71.925 \\
Sig. (1-tailed) & .000 & .0005 & .000 \\
Mean Difference & -3.26819 & -.77685 & -.98545 \\
Std. Error Difference & .81093 & .22412 & .20404 \\
\hline
\end{tabular}

\section{Conclusion}

Research showed that there was no difference in students' germane load who implement the worked-example method with self-explanation prompting and students who implement worked-example methods without self-explanation prompting. However, it was revealed that the students' germane load in the two research groups in the high category. This indicates that learning using the worked-example method is able to foster students' germane load. However, these results have not yet shown evidence that self-explanation prompting is capable of fostering students' germane load. Mean- while, Kalyuga (2011) states that there is an association between germane load and learning objectives.

When students achieve learning objectives, then the learning method is able to foster students' germane load. To assess the learning objectives, the posttest was arranged to be in accordance with the indicators of learning objectives.

The results stated that students who implement the worked-example method with self-explanation prompting had better test scores than students who implement the worked-example method without selfexplanation prompting. This result is suffi- 
cient to provide evidence that the use of worked-example with self-explanation prompting is able to foster students' germane load in the multivariable calculus course.

Therefore, the worked-example learning method in mathematics learning, especially on multivariable calculus is important to implement. Thus, through the findings of this study, the worked-example method with self-explanation prompting can be considered to be implemented on calculus learning to enhance students' attention to the subject matter and improve their learning outcomes.

\section{References}

Baddeley, A. (1992). Working Memory. Science, 255, 556-559.

Baddeley, A. (2003). Working memory: looking back and looking forward. Nature Reviews. Neuroscience, 4(10), 829-39.

Baddeley, A. (2010, March 23). Working memory. Current Biology, 20(4), 136140.

Baddeley, A. (2012). Working memory: theories, models, and controversies. Annual Review of Psychology, 63, 129.

Berthold, K., Röder, H., Knörzer, D., Kessler, W., \& Renkl, A. (2011). The double-edged effects of explanation prompts. Computers in Human Behavior, 27(1), 69-75.

Bokosmaty, S., Sweller, J., \& Kalyuga, S. (2015). Learning Geometry Problem Solving by Studying Worked Examples: Effects of Learner Guidance and Expertise. American Educational Research Journal, 52(2), 307-333.

Booth, J. L., Lange, K. E., Koedinger, K. R., \& Newton, K. J. (2013). Using example problems to improve student learning in algebra: Differentiating between correct and incorrect examples. Learning and Instruction, 25, 24-34.

Clark, R. C., Nguyen, F., \& Sweller, J. (2011). Efficiency in Learning; Evidence-Based Guidlines to Manage
Cognitive Load. New York: John Wiley and Son Ltd.

Debue, N., \& Leemput, C. van de. (2014). What does germane load mean? An empirical contribution to the cognitive load theory. Frontiers in Psychology, 5(October), 1-12.

Fraenkel, J. R., Wallen, N. E., \& Hyun, H. H. (2012). How to Design and Evaluate Research in Education (8th ed.). New York: McGraw-Hill.

Hausmann, R. G. M., Nokes, T. J., VanLehn, K., \& Gershman, S. (2009). The Design of Self-explanation Prompts: The Fit Hypothesis. In 31st Annual Conference of the Cognitive Science Society Cognitive Science (pp. 2626-2631).

Hefter, M. H., Renkl, A., Riess, W., Schmid, S., Fries, S., \& Berthold, K. (2015). Effects of a training intervention to foster precursors of evaluativist epistemological understanding and intellectual values. Learning and Instruction, 39, 11-22.

Hodds, M., Alcock, L., \& Inglis, M. (2014). Self-Explanation Training Improves Proof Comprehension. Journal for Research in Mathematics Education, 45(1), 62-101.

Hu, F.-T., Ginns, P., \& Bobis, J. (2015). Getting the point: Tracing worked examples enhances learning. Learning and Instruction, 35, 85-93.

Jamieson, S. (2004). Likert scales: how to (ab)use them. Medical Education, 38, 1212-1218.

Job, P., \& Schneider, M. (2014). Empirical positivism, an epistemological obstacle in the learning of calculus. ZDM International Journal on Mathematics Education, 46(4), 635-646.

Kalyuga, S. (2011). Cognitive Load Theory: How Many Types of Load Does It Really Need? Educational Psychology Review, 23(1), 1-19.

Kashefi, H., Ismail, Z., \& Yusof, Y. M. (2010). Obstacles in the learning of twovariable functions through mathematical thinking approach. Procedia - Social and Behavioral Sciences, 8(5), 173-180. 
Khateeb, M. (2008). Cognitive Load Theory and Mathematics Education. (Thesis). University of New South Wales.

Leahy, W., \& Sweller, J. (2008). The Imagination Effect Increases with an Increased Intrinsic Cognitive Load. Applied Cognitive Psychology, 22(2008), 273-283.

Martínez-Planell, R., Gonzalez, A. C., DiCristina, G., \& Acevedo, V. (2012). Students' conception of infinite series. Educational Studies in Mathematics, 81(2), 235-249.

Mattys, S. L., Barden, K., \& Samuel, A. G. (2014). Extrinsic cognitive load impairs low-level speech perception. Psychonomic Bulletin and Review, 21(3), 748-754.

Miller, G. A. (1956). The magical number seven, plus or minus two: some limits on our capacity for processing information. Psychological Review, 63(2), 81-97.

Moore, R. C. (1994). Making the Transition to Formal Proof. Journal of Educational Studies in Mathematics, 27, 249-266.

Moru, E. K. (2009). Epistemological obstacles in coming to understand the limit of a function at undergraduate level: A case from the national university of lesotho. International Journal of Science and Mathematics Education.

Norman, G. (2010). Likert scales, levels of measurement and the "laws." Advance in Health Science Education, 15, 625632.

Nursyahidah, F., \& Albab, I. U. (2017). Investigating Student Difficulties on Integral Calculus Based on Critical Thinking Aspects. Jurnal Riset Pendidikan Matematika, 4(2), 211-218.

Orton, A. (1983). Students' understanding of integration. Educational Studies in Mathematics.

Paas, F., \& Gog, T. Van. (2006). Optimising worked example instruction: Different ways to increase germane cognitive load. Learning and Instruction, 16(411), 87-91.
Paas, F., \& Kester, L. (2006). Learner and information characteristics in the design of powerful learning environments. Applied Cognitive Psychology, 20(3), 281-285.

Peterson, L. R., \& Peterson, M. J. (1959). Journal of Experimental Psychology, 58(3), 193-198.

Purcell, E. J., Varberg, D., \& Rigdon, S. E. (2007). Calculus (9th Editio). New Jersey: Prentice-Hall Inc.

Rau, M. a, Aleven, V., \& Rummel, N. (2015). Successful Learning With Multiple Graphical Representations and Self-Explanation Prompts. Journal of Educational Psychology, 107(1), 30-46.

Renkl, A. (2017). Learning from workedexamples in mathematics: students relate procedures to principles. ZDM, 1-14.

Retnowati, E., Ayres, P., \& Sweller, J. (2010). Worked example effects in individual and group work settings. Educational Psychology, 30(February 2015), 349-367.

Rittle-Johnson, B., Loehr, A. M., \& Durkin, K. (2017). Promoting self-explanation to improve mathematics learning: A metaanalysis and instructional design principles. Zdm, 0(0123456789), 0.

Roelle, J., Hiller, S., Berthold, K., \& Rumann, S. (2017). Example-based learning: The benefits of prompting organization before providing examples. Learning and Instruction, 49, 1-12.

Rourke, A., \& Sweller, J. (2009). The worked-example effect using ill-defined problems: Learning to recognise designers' styles. Learning and Instruction, 19(2), 185-199.

Salden, R. J. C. M., Koedinger, K. R., Renkl, A., Aleven, V., \& McLaren, B. M. (2010). Accounting for Beneficial Effects of Worked Examples in Tutored Problem Solving. Educational Psychology Review, 22(4), 379-392.

Santosa, C. A. H. F. (2013). Mengatasi Kesulitan Mahasiswa ketika Melakukan Pembuktian Matematis Formal. Jurnal Pengajaran MIPA, 18(2), 152-160. 
Santosa, C. A. H. F., Suryadi, D., \& Prabawanto, S. (2016). Pengukuran efisiensi kognitif matematis di perguruan tinggi. In Seminar Nasional Matematika dan Pendidikan Matematika. Cirebon: Fakultas Keguruan dan Ilmu Pendidikan, Universitas Swadaya Gunung Jati.

Santosa, C. A. H. F., Suryadi, D., Prabawanto, S., \& Syamsuri. (n.d.). The role of worked-example in enhancing students' self-explanation and cognitive efficiency in calculus instruction. Jurnal Riset Pendidikan Matematika.

Stewart, J. (2012). Calculus. (L. Covello, L. Neustaetter, J. Staller, \& M. Ross, Eds.) (Seventh Ed). Belmont: Brooks/Cole.

Sweller, J. (2008). Human Cognitive Architecture. In J. M. Spector, M. D. Merril, J. J. G. van Merriënboer, \& M. P. Driscoll (Eds.), Handbook of Research on Educational Communications and Technology (pp. 369-381). New York: Lawrence Erlbaum Associates.

Sweller, J. (2010). Element interactivity and intrinsic, extraneous, and germane cognitive load. Educational Psychology Review, 22(2), 123-138.
Sweller, J. (2011). Cognitive Load Theory. In J. P. Mestre \& B. H. Ross (Eds.), The Psychology of Learning and Cognition in Education (pp. 37-74). Waltham: Elsevier.

Sweller, J., \& Sweller, S. (2006). Natural information processing systems. Evolutionary Psychology, 4, 434-458.

Tall, D. (2008). The Transition to Formal Thinking in Mathematics, 20(2), 5-24.

Van Gog, T., Kester, L., \& Paas, F. (2011). Effects of worked examples, exampleproblem, and problem-example pairs on novices' learning. Contemporary Educational Psychology, 36(3), 212218.

Van Loon-Hillen, N., Van Gog, T., \& BrandGruwel, S. (2012). Effects of worked examples in a primary school mathematics curriculum. Interactive Learning Environments, 20(1), 89-99.

Yanuarto, W. N. (2016). Students ' Awareness on Example and NonExample Learning in Geometry Class. International Electronic Journal Of Mathematics Education, 11(10), 35113519. 